American J. of Engineering and Applied Sciences 3 (4): 620-628, 2010

ISSN 1941-7020

(C) 2010 Science Publications

\title{
Reliability Assessment of Buckling Strength for Compressed Cylindrical Shells with Interacting Localized Geometric Imperfections
}

\author{
${ }^{1}$ Jalal El Bahaoui, ${ }^{1}$ Abdellatif Khamlichi, ${ }^{1}$ Larbi El Bakkali and ${ }^{2}$ Ali Limam \\ ${ }^{1}$ Modeling and Simulation of Mechanical Systems Laboratory, Department of Physics, \\ Faculty of Sciences at Tetouan, University Abdelmalek Essaadi, \\ BP 2121, M'hannech, 93002, Tetouan, Morocco \\ ${ }^{2}$ Laboratory of Civil and Environmental Engineering, \\ Department of Civil Engineering and Urbanism, \\ National Institute of Applied Sciences at Lyon, Albert Einstein Avenue, \\ Villeurbanne 69662, France
}

\begin{abstract}
Problem statement: Elastic cylindrical shells are common structures in the fields of civil engineering and engineering mechanics. These thin-walled constructions may undergo buckling when subjected to axial compression. Buckling limits to large extent their strength performance. This phenomenon depends hugely on the initial distributed or localized geometric imperfections that are present on the shell structure. Localized geometric imperfections result in general from the operation of welding strakes to assemble the shell structure. In this study, reliability of buckling strength as it could be affected by shell material and geometry parameters was investigated. The localized geometric imperfections were chosen to be entering and having either a triangular or a wavelet form. Interaction between three localized imperfections had also been considered. Approach: A special software package which was dedicated to buckling analysis of quasi axisymmetric shells was used in order to compute the buckling load via the linear Euler buckling procedure. A set of five factors including shell aspect ratios, defect characteristics and the distance separating the localized initial geometric imperfections had been found to govern the buckling problem. A parametric study was performed to determine their relative influence on the buckling load reduction. Reliability analysis was carried out by using first order reliability method. Results: Wavelet imperfection was found to be more severe than triangular form in the range of low amplitude imperfections. It was shown also by comparison with the single imperfection case that further diminution of the critical load is obtained for three interacting imperfections. The interval distance separating the localized geometric imperfections was found to have important influence on the reliability index. Conclusion/Recommendations: In the he range of investigated parameters, reliability was found to increase with the distance separating the localized geometric imperfections. This can help performing optimal design of assembled strakes.
\end{abstract}

Key words: Buckling, shells, geometric imperfections, finite element method, reliability

\section{INTRODUCTION}

Thin axisymmetric cylindrical shells are used in many fields of structural engineering as essential components: silos and tanks. A common feature of these structures is that whatever the manufacturing process is used, the final geometry is never perfect. Geometric imperfections affect always the ideal desired nominal form in the real assembled shell. Control and optimization of processes used for shell manufacturing and assembling may well decrease imperfection amplitudes, but could never eliminate them. Precise measurements would reveal definitely small geometric imperfections having in general the same order of magnitude than shell thickness.

During their service life, shell structures may be subjected to various kinds of loadings, such as axial compression, external/internal pressure, flexure or torsion. For thin cylindrical shells under uniform axial compression, the buckling strength constitutes always the most adverse design issue. Calculation of the buckling load as it could be affected by the presence of

Faculty of Sciences at Tetouan, University Abdelmalek Essaadi, BP 2121, M'hannech, 93002, Tetouan, Morocco Tel: +212 667795068 Fax: +212 539994500 
various kinds of geometric imperfections represents therefore a main step to enhance shell design. The aim is to know how to achieve cost effective structural design with relevant margins of safety.

Several studies have been reported in the literature which deals with the effect of imperfections on strength buckling of thin shell structures. Arbocz (1987; 2005) have studied experimentally buckling of cylindrical shells subjected to general imperfections. They have shown that a huge reduction of the buckling critical load could be obtained by taking into account initial geometric imperfections. Van der Heijden (2009) has given an extensive review study about the effect of geometric imperfections on shell buckling strength. Various other general investigations have been achieved since then. They have dealt with the effect of both distributed and/or localized imperfections on reduction of the buckling load: Arbocz (2005); Yamaki (1984); Bushnell (1989); Godoy (1993) and Gusic et al. (2000). Kim and Kim (2002) have considered a generalized initial geometric imperfection having a modal superposition form. Studying the buckling strength of cylindrical shells and tanks built on soft or rigid foundations and subjected to axially compressive loads, they have found that the buckling load decreases significantly as the amplitude of initial geometric imperfection increases.

All the previous literature agrees on the fact that imperfections reduce drastically the buckling load of elastic cylindrical shells when subjected to axial compression. The obtained reduction depends however on the nature of initial geometric imperfections that disturb the shell structure. It has been found also that reduction of the buckling load is, in general, more severe in case of distributed imperfections than for localized ones.

Imperfections for which maximum reduction of the buckling load is obtained are artificial and purely theoretical like for example the well known generalized Van der Heijden (2009) imperfection. They might hence never be encountered in practice in case of real shells. Therefore, investigation has been motivated by the analysis of buckling in the presence of typical imperfections obtained from modal analysis of measured data or by considering realistic imperfection shapes such as those resulting from welding operations performed during assembling of shell parts. Steel silos and tanks are constructed from plates which are rolled to obtain the correct curvature and subsequently welded together to form strakes. The strakes are brought together then to assemble by welding the complete shell structure. At circumferential welds localized geometric imperfections develop. The welding profile can vary from one shell to another but a common feature of welds is that they can be characterized by only two parameters: The amplitude and wavelength. Measurements have revealed that mostly axisymmetric imperfections occur in shell structures assembled by welding, Ding et al. (1996). Hutchinson et al. (1971) and Khamlichi et al. (2004) investigated localized ax symmetric imperfections and have shown that a single axisymmetric imperfection is sufficient to yield large effect on buckling strength. Hubner et al. (2006) have used numerical methods to deal with weld-induced imperfections and have obtained results that corroborate those obtained by the previous authors. Jamal et al. (1999) have analyzed the influence of localized imperfections on the buckling load for long cylindrical shells under axial compression by using an analytical method based on interaction modes. Analytical formulas were derived to predict the reduction of the critical buckling load. Considering a single localized imperfection, the strength of thin cylindrical shell structures has been found to be highly dependent on the nature and magnitude of imperfections. Combining shell theory with actual field imperfection measurements, Pircher et al. (2001) have found that three parameters governed the shape of the surveyed weld imperfections: The amplitude (depth), the wavelength (width) and the roundness. Mathon and Limam (2006) have compared the relative influence of several localized imperfections on reduction of the buckling load of shells subjected to axial compression or to flexure. They have shown that an entering triangular imperfection shape has the most severe effect on buckling strength.

In almost all the previous works only single geometric imperfections were considered, Khamlichi et al. (2010) have analyzed interaction effects that could result from two geometric imperfections having entering triangular form. They have demonstrated that further reduction of the buckling load is reached with two localized imperfections. They have found also that the distance separating two consecutive imperfections is an additional parameter which has a significant influence on the shell buckling strength.

Shell resistance as well as the loads applied on it depend on several variables, most of which are random. Therefore, the use of a probabilistic approach in carrying out design of shell structures enables to tackle in a more realistic fashion structural safety purposes.

Structural reliability is concerned with the calculation and prediction of the probability to exceed a limit state for a given structure at any stage during its life. This approach gains nowadays a large number of engineering fields due to its rational character.

The classical way of integrating uncertainties in design of structures consists in using safety factors that 
are based on engineering judgment and previous experience with analogous structures. This approach is questionable because it yields either to under estimation of the involved uncertainties and therefore to adverse results about strength loss, or sometimes to over estimation of the real involved uncertainties with as a result poor economic design.

Buckling of imperfect shells with small random initial geometric imperfections has been studied by several investigators like Hansen (1977) and Schenk and Schueller (2003). Later Elishakoff et al. (1987) has proposed a method which makes it possible to integrate the results of measured initial imperfections into the buckling analysis of shells. The proposed approach which he has introduced is based on the concept of a reliability function:

$$
\mathrm{R}(\lambda)=\mathrm{P}(\Lambda \geq \lambda)
$$

Where:

$\lambda=$ A normalized parameter fixing the threshold buckling load

$\Lambda=$ Normalized random actual buckling load

The knowledge of the reliability function permits the evaluation of the allowable load $\lambda_{\mathrm{a}}$ which is defined as the load level enabling the desired reliability to be reached. Initially Elishakoff et al. (1987) has used the Monte Carlo method to obtain the reliability function $\mathrm{R}(\lambda)$. Elishakoff et al. (1987) have shown that when replacing the Monte Carlo Method by the first-order, second-moment method the number of deterministic buckling load calculations needed to derive the reliability function $R(\lambda)$ is greatly reduced.

Several recent investigations have been dedicated to shell buckling strength within the framework of reliability analysis. Arbocz and Hol (1995) has used an approximate analytical solution in conjunction with a random database description of geometric imperfections. Papadopoulos and Papadrakakis (2005) have introduced a spectral representation of the geometric imperfection within the stochastic finite element method.

One should notice that when considering localized imperfections a lot of Fourier series terms are needed to represent with sufficient accuracy the geometric imperfection, the spectral method may result to be cumbersome and a direct method is needed. Moreover, to our knowledge, the case of interacting localized imperfections has never been addressed within the framework of reliability analysis.

The objective of this study is to assess reliability of shell buckling strength as it could be affected by three initial localized geometric imperfections. Thin axisymmetric cylindrical shells made of homogeneous and isotropic elastic material are considered. They are assumed to deform under a purely axisymmetric strain state under the action of axially uniform compressive loads.

\section{Modeling thin cylindrical shells with localized geometric imperfections: Shell equations} incorporating the effect of initial imperfections are used, Markus (1988), to analyze shell buckling strength for the particular case of thin circular cylindrical shells subjected to quasi-static uniform compressive loads. A variant of this model has been used by Gusic et al. (2000). Relevant finite element modeling of these equations can be straightforwardly carried out by means of Coque element developed under Stanlax software package, (Gusic et al., 2000). Stanlax software is based on an analytical expansion in terms of the circumferential variable and finite element modeling of axial dependant quantities. The initial imperfections are included in the shell model formulation under the assumption of small perturbations to shell geometry. Stanlax software is used in the following in order to model the imperfect axisymmetric cylindrical shell having three localized geometric imperfections. Stanlax offers either a linear Euler buckling analysis mode or a full non linear iterative method for the computation of buckling load. For shells under axial compression, it was shown that a linear Euler calculus is sufficient.

The shell material is linear elastic having Young's modulus E and Poisson's coefficient v. The geometric imperfections are assumed to be localized in the median zone of the shell length in positions that are sufficiently far from the shell ends in order to avoid interactions with the boundary conditions. The selected boundary conditions are those corresponding to clamped shell ends.

As shown in Fig. 1, parameters $t, H$ and $\mathrm{R}$ designate respectively shell thickness, shell length and shell mean radius.

Let $\mathrm{A}$ and $\mathrm{d}$ be respectively the geometric imperfection amplitude and the distance separating two contiguous imperfections. Denoting $\lambda_{\mathrm{c}}=1.72 \sqrt{\mathrm{Rt}}$, the following non dimensional zed parameters are defined for the shell buckling problem (Fig. 2):

- $\mathrm{R} / \mathrm{t}$ radius to thickness ratio

- $\mathrm{H} / \mathrm{R}$ length to radius ratio

- $\mathrm{A} / \mathrm{t}$ defect amplitude parameter

- $\mathrm{H} / \mathrm{d}$ height to defect interval scale ratio

- $\alpha=\lambda / \lambda_{\mathrm{c}}$ defect wave length to critical wave length 


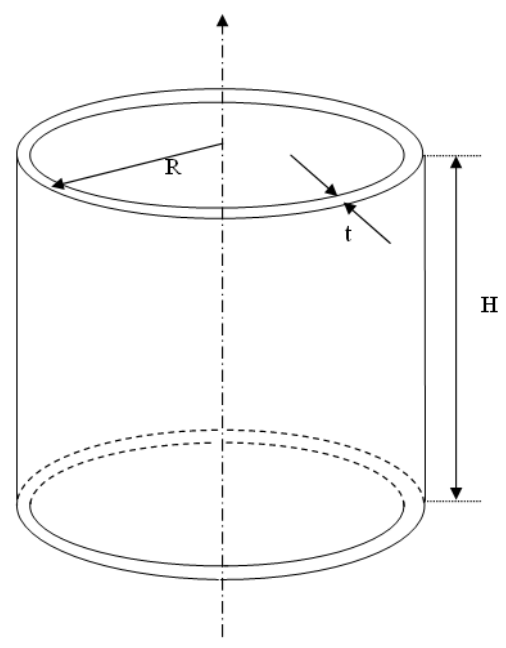

Fig. 1: Shell geometry

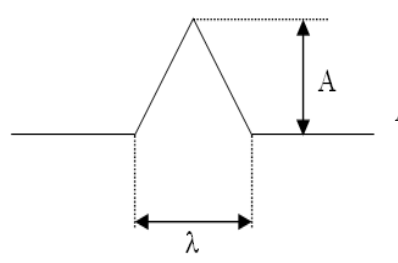

(a)

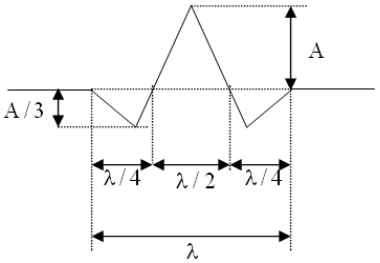

(b)
Fig. 2: Shape of the localized imperfections; (a) Triangular geometric imperfection; (b) Wavelet geometric imperfection

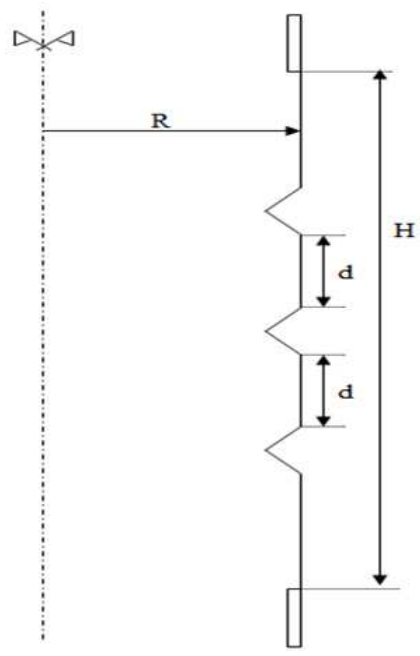

Fig. 3: Configurations of triangular localized geometric imperfections

During the parametric study to follow, the shell radius is maintained constant at the value $R=135 \mathrm{~mm}$ while the other parameters are varied. The considered localized triangular geometric imperfections have the configuration shown in Fig. 3. They are directed inwards the shell radius. Stanlax software package enables for each combination of parameters to compute the shell buckling load under the applied uniform axial compression. Use is made of shell element Coque and convergence assessment is performed in order to determine the optimal mesh size to be employed.

Reliability analysis: The buckling strength capacity $\mathrm{R}$ and the axial loading $\mathrm{S}$ applied on the shell structure are random variables in nature. The main objective of reliability analysis is to ensure that $S$ never exceeds $R$ with regards to an accepted margin of risk. Because $\mathrm{R}$ and $\mathrm{S}$ are functions of basic design variables, to investigate the performance of shell under buckling loading requires specifying a limit state equation in terms of these basic variables. This limit state equation is referred to as the performance or state function and is expressed as:

$$
\mathrm{g}\left(\mathrm{X}_{\mathrm{i}}\right)=\mathrm{R}-\mathrm{S}
$$

where, $\mathrm{X}_{\mathrm{i}}, \mathrm{i}=1, \ldots, \mathrm{n}$ are the basic design variables assumed to be uncorrelated and reduced such as $\mathrm{E}\left(\mathrm{X}_{\mathrm{i}}\right)=0$ and $\mathrm{V}\left(\mathrm{X}_{\mathrm{i}}\right)=1$.

The limit state of the system can then be expressed as:

$\mathrm{g}\left(\mathrm{X}_{\mathrm{i}}\right)=0$

The curve $g\left(X_{i}\right)=0$ represents the failure surface while $g\left(X_{i}\right)<0$ represents the safe region and $g\left(X_{i}\right)>0$ is the failure region.

The distance $\mathrm{D}$, from the origin of $\mathrm{X}$ space to a point $\mathrm{X}=\left[\begin{array}{lll}\mathrm{X}_{1} & \ldots & \mathrm{X}_{\mathrm{n}}\end{array}\right]^{\mathrm{t}}$, where $\mathrm{t}$ denotes the transposing operation, which is located on the failure surface $\mathrm{g}\left(\mathrm{X}_{\mathrm{i}}\right)=0$ writes:

$\mathrm{D}=\sqrt{\mathrm{X}_{1}^{2}+\ldots+\mathrm{X}_{\mathrm{n}}^{2}}$

The point on the failure surface $X^{*}=\left[\begin{array}{lll}X_{1}^{*} & \ldots & X_{n}^{*}\end{array}\right]^{t}$ having the minimum distance to the origin can be obtained by minimizing the function $\mathrm{D}$ when subjected to the constraint $\mathrm{g}\left(\mathrm{X}_{\mathrm{i}}\right)=0$. Lagrange multiplier method could be used. The lagrangian $\mathrm{L}$ writes:

$\mathrm{L}=\mathrm{D}+\lambda \mathrm{g}\left(\mathrm{X}_{\mathrm{i}}\right)=\sqrt{\mathrm{X}_{1}^{2}+\ldots+\mathrm{X}_{\mathrm{n}}^{2}}+\lambda \mathrm{g}\left(\mathrm{X}_{1}, \ldots, \mathrm{X}_{\mathrm{n}}\right)$ 
where, $\lambda$ is the Lagrange multiplier.

Minimizing $L$, we obtain a system of $n+1$ equations having $\mathrm{n}+1$ unknown as:

$$
\begin{aligned}
& \frac{\partial \mathrm{L}}{\partial \mathrm{X}_{\mathrm{i}}}=\frac{\mathrm{X}_{\mathrm{i}}}{\sqrt{\mathrm{X}_{1}^{2}+\ldots+\mathrm{X}_{\mathrm{n}}^{2}}}+\lambda \frac{\partial \mathrm{g}}{\partial \mathrm{X}_{\mathrm{i}}}\left(\mathrm{X}_{\mathrm{i}}\right)=0 \\
& \frac{\partial \mathrm{L}}{\partial \lambda}=\mathrm{g}\left(\mathrm{X}_{\mathrm{i}}\right)=0
\end{aligned}
$$

Solution of this system yields the most probable failure point $\left[\begin{array}{lll}\mathrm{X}_{1}^{*} & \ldots & \mathrm{X}_{\mathrm{n}}^{*}\end{array}\right]^{\mathrm{t}}$.

The minimum distance from the origin to the curve representing the failure surface is termed the reliability index and is given by:

$\beta=-\frac{\left(\nabla g^{*}\right)^{t} X^{*}}{\sqrt{\left(\nabla g^{*}\right)^{t} \nabla g^{*}}}$

with $\nabla \mathrm{g}^{*}$ represents the gradient vector of $\mathrm{g}$ evaluated at the optimum point.

Design is said to be satisfactory if the failure probability $\mathrm{P}_{\mathrm{f}}=\mathrm{P}(\mathrm{g}(\mathrm{X})<0)$ does not exceed a given threshold. Estimating the reliability index and the failure probability is performed in the following by means of FORM method.

\section{MATERIALS AND METHODS}

Considering homogeneous elastic axisymmetric cylindrical shells having initial geometric imperfections under the action of uniform axial compression, the shell buckling strength can be computed as follows. The shell geometry and material parameters as well as the features of initial geometric imperfections are fixed at first. Then, using Stanlax software package the buckling load is readily obtained. Investigation of the relative effect of the intervening factors on reliability index of the shell buckling load can be performed according to the following methodology. At first, the shell aspect ratios, for which maximum effect on the buckling strength is observed, are determined. Fixing the shell geometry configuration at the most adverse case with respect to shell aspect ratios, fixing also the distance separating two successive imperfections, a parametric study can be conducted by varying the two free remaining factors: namely imperfection amplitude and wavelength. A full factorial design of experiment table can be used for that. Here, three levels were chosen for each variable resulting in total number of 27 combinations.

The obtained results, for each value of the distance separating the initial geometric imperfections, in terms of shell bucking strength can be treated via non linear regression techniques. Quadratic regressions have been shown to be quite adequate to get accurate response surface models in the present problem. Explicit quadratic polynomial approximations giving the shell bulking load as function of imperfection amplitude and wavelength were so derived to estimate the buckling load for each given realization of parameters.

Assuming that the imperfection amplitude and wavelength are random variables, the response surface models can be used to perform reliability analysis according to FORM method. Specialized reliability software was used for that purpose. Reliability index parameterized by the distance separating the localized initial geometric imperfections can then be obtained. The reliability probability is also obtained in the same conditions. This allows depicting for each distance separating the localized imperfections a curve giving the realibility probability as function of the chosen design shell buckling load.

\section{RESULTS AND DISCUSSION}

A preliminary study has assessed that the shell aspect parameters that yield the most adverse buckling load are given by $\mathrm{H} / \mathrm{R}=3$ and $\mathrm{R} / \mathrm{t}=1500$, (Khamlichi et al., 2010).

Let's consider a shell satisfying the previous aspects conditions with geometric and material properties that correspond to: $\mathrm{R}=135 \mathrm{~mm}, \mathrm{H}=405$ $\mathrm{mm}, \mathrm{t}=0.09 \mathrm{~mm}, \mathrm{E}=7 \times 10^{10} \mathrm{~Pa}$ and $v=0.3$. The classical buckling load is:

$$
\sigma_{\mathrm{cl}}=\frac{\mathrm{E}}{\sqrt{3\left(1-v^{2}\right)}} \times \frac{\mathrm{t}}{\mathrm{R}}=28.233 \times 10^{6} \mathrm{~Pa}
$$

Considering three localized geometric imperfections matching the following parameters: $\alpha$, $\mathrm{A} / \mathrm{t}$ and $\mathrm{d}$, their effect on shell buckling strength can be straightforwardly investigated by means of Stanlax software which provides the actual buckling load $\sigma_{\mathrm{cr}}$. For the case where $\mathrm{H} / \mathrm{d}=40.5$ the obtained results are presented in Fig. 4 in terms of $\sigma_{\mathrm{cr}} / \sigma_{\mathrm{c} 1}$ versus parameter $\mathrm{A} / \mathrm{t}$ for both triangular and wavelet geometric imperfections.

Full factorial design of experiment tables have been considered for each imperfection type: triangular or wavelet. Three levels were chosen for the intervening three factors according to Table 1 and 2 . The obtained results in terms of the reduced buckling load $\sigma_{\mathrm{cr}} / \sigma_{\mathrm{c} 1}$ as function of parameters $\mathrm{x}=\alpha, \mathrm{y}=\mathrm{A} / \mathrm{t}$ and $\mathrm{d}$ are listed in Table 1 and 2. 
Am. J. Engg. \& Applied Sci., 3 (4): 620-628, 2010

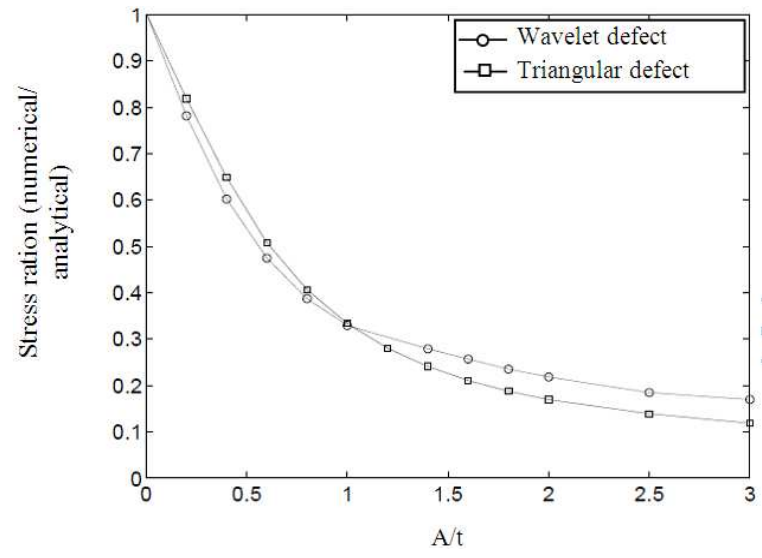

Fig. 4: Comparison of the buckling load for the two considered localized imperfection shapes

Table 1: The reduced buckling load as function of given combinations of parameters, triangular geometric imperfection

\begin{tabular}{|c|c|c|c|}
\hline $\mathrm{x}$ & $\mathrm{y}$ & $\mathrm{d}$ & $\sigma_{\mathrm{cr}} / \sigma_{\mathrm{cl}}$ \\
\hline 1 & 1 & 50 & 0.4446 \\
\hline 1 & 1 & 100 & 0.4945 \\
\hline 1 & 1 & 150 & 0.5027 \\
\hline 1 & 2 & 50 & 0.3061 \\
\hline 1 & 2 & 100 & 0.3863 \\
\hline 1 & 2 & 150 & 0.3903 \\
\hline 1 & 3 & 50 & 0.2482 \\
\hline 1 & 3 & 100 & 0.3454 \\
\hline 1 & 3 & 150 & 0.3968 \\
\hline 2.5 & 1 & 50 & 0.3449 \\
\hline 2.5 & 1 & 100 & 0.3626 \\
\hline 2.5 & 1 & 150 & 0.3723 \\
\hline 2.5 & 2 & 50 & 0.1755 \\
\hline 2.5 & 2 & 100 & 0.2005 \\
\hline 2.5 & 2 & 150 & 0.2126 \\
\hline 2.5 & 3 & 50 & 0.1240 \\
\hline 2.5 & 3 & 100 & 0.1452 \\
\hline 2.5 & 3 & 150 & 0.1721 \\
\hline 3 & 1 & 50 & 0.3728 \\
\hline 3 & 1 & 100 & 0.3807 \\
\hline 3 & 1 & 150 & 0.3897 \\
\hline 3 & 2 & 50 & 0.1892 \\
\hline 3 & 2 & 100 & 0.2037 \\
\hline 3 & 2 & 150 & 0.2131 \\
\hline 3 & 3 & 50 & 0.1301 \\
\hline 3 & 3 & 100 & 0.1416 \\
\hline 3 & 3 & 150 & 0.1651 \\
\hline
\end{tabular}

Fixing the distance, d, separating two successive geometric imperfections, a response surface model that gives the reduced buckling load $\sigma_{\mathrm{cr}} / \sigma_{\mathrm{c} 1}$ as function of the imperfection characteristics $\mathrm{x}$ and $\mathrm{y}$ can be derived. Quadratic regression models of $\sigma_{\mathrm{cr}} / \sigma_{\mathrm{cl}}=\mathrm{P}(\mathrm{x}, \mathrm{y})$ can be steadily identified by using the Matlab command regress and $\sigma_{\mathrm{cr}} / \sigma_{\mathrm{c} 1}$ results related to a given distance $\mathrm{d}$ such they appear respectively in Table 1 and 2.

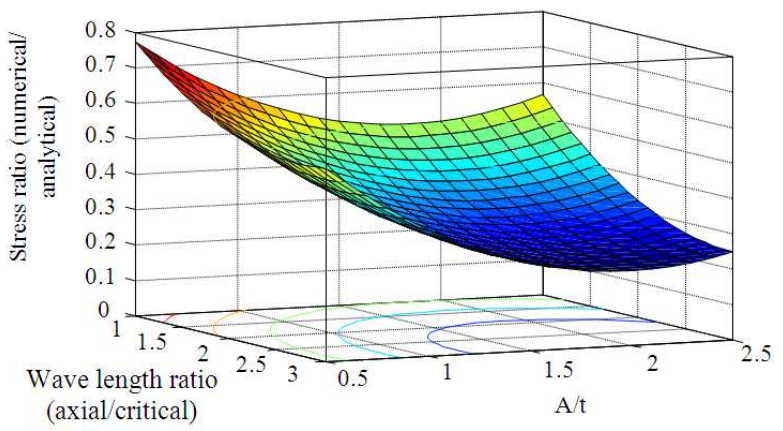

Fig. 5: Response surface for triangular geometric imperfections; $\mathrm{d}=50 \mathrm{~mm}$

Table 2: The reduced buckling load as function of given combinations of parameters, wavelet geometric imperfection

\begin{tabular}{llrl}
\hline $\mathrm{x}$ & $\mathrm{y}$ & $\mathrm{d}$ & $\sigma_{\mathrm{cr}} / \sigma_{\mathrm{cl}}$ \\
\hline 1 & 0.25 & 50 & 0.8810 \\
1 & 0.25 & 100 & 0.8434 \\
1 & 0.25 & 150 & 0.9282 \\
1 & 0.50 & 50 & 0.7562 \\
1 & 0.50 & 100 & 0.6512 \\
1 & 0.50 & 150 & 0.7967 \\
1 & 0.75 & 50 & 0.6766 \\
1 & 0.75 & 100 & 0.5370 \\
1 & 0.75 & 150 & 0.7078 \\
2.5 & 0.25 & 50 & 0.7375 \\
2.5 & 0.25 & 100 & 0.7480 \\
2.5 & 0.25 & 150 & 0.7600 \\
2.5 & 0.50 & 50 & 0.5405 \\
2.5 & 0.50 & 100 & 0.5472 \\
2.5 & 0.50 & 150 & 0.5577 \\
2.5 & 0.75 & 50 & 0.4282 \\
2.5 & 0.75 & 100 & 0.4297 \\
2.5 & 0.75 & 150 & 0.4399 \\
3 & 0.25 & 50 & 0.7288 \\
3 & 0.25 & 100 & 0.7370 \\
3 & 0.25 & 150 & 0.7521 \\
3 & 0.50 & 50 & 0.5253 \\
3 & 0.50 & 100 & 0.5311 \\
3 & 0.50 & 150 & 0.5475 \\
3 & 0.75 & 50 & 0.4070 \\
3 & 0.75 & 100 & 0.4099 \\
3 & 0.75 & & 0.4300 \\
\hline & & &
\end{tabular}

Table 3 gives the quadratic regression models associated to the two geometric imperfection types according as function of the interval distance $d$ separating the defects. Figure 5 gives the response surface obtained for the triangular geometric imperfections with $\mathrm{d}=50 \mathrm{~mm}$.

Considering the imperfection amplitude and wavelength as random variables obeying to lognormal distributions of probability for which the mean and the standard deviation are given in Table 4, Fig. 6 and 7 present the index of reliability as function of the allowable design buckling load for different values of distance $\mathrm{d}$. 
Am. J. Engg. \& Applied Sci., 3 (4): 620-628, 2010

Table 3: The identified quadratic response models

\begin{tabular}{llll}
\hline Imperfection type & Distance $\mathrm{d}(\mathrm{mm})$ & $\mathrm{R}^{2}$ & Quadratic response surface \\
\hline Triangular & 50 & 0.91 & $\mathrm{P}(\mathrm{x}, \mathrm{y})=0.9027-0.2508 \mathrm{x}-0.3019 \mathrm{y}-0.01080 \mathrm{xy}+0.05533 \mathrm{x}^{2}+0.05383 \mathrm{y}^{2}$ \\
& 100 & 0.91 & $\mathrm{P}(\mathrm{x}, \mathrm{y})=0.9469-0.2919 \mathrm{x}-0.2446 \mathrm{y}-0.02259 \mathrm{xy}+0.06343 \mathrm{x}^{2}+0.04816 \mathrm{y}^{2}$ \\
Wavelet & 150 & 0.90 & $\mathrm{P}(\mathrm{x}, \mathrm{y})=0.9558-0.2783 \mathrm{x}-0.2677 \mathrm{y}-0.03007 \mathrm{xy}+0.06288 \mathrm{x}^{2}+0.06111 \mathrm{y}^{2}$ \\
& 50 & 0.95 & $\mathrm{P}(\mathrm{x}, \mathrm{y})=1.302-0.2572 \mathrm{x}-0.8649 \mathrm{y}-0.1227 \mathrm{xy}+0.05244 \mathrm{x}^{2}+0.5737 \mathrm{y}^{2}$ \\
& 100 & 0.98 & $\mathrm{P}(\mathrm{x}, \mathrm{y})=1.224-0.1229 \mathrm{x}-1.247 \mathrm{y}-0.01960 \mathrm{xy}+0.01843 \mathrm{x}^{2}+0.6553 \mathrm{y}^{2}$ \\
& 150 & 0.96 & $\mathrm{P}(\mathrm{x}, \mathrm{y})=1.414-0.3260 \mathrm{x}-0.9096 \mathrm{y}-0.1088 \mathrm{xy}+0.06582 \mathrm{x}^{2}+0.5706 \mathrm{y}^{2}$ \\
\hline
\end{tabular}

Table 4: Mean and standard deviation of random variables

\begin{tabular}{llll}
\hline & Random variable & Mean & SD \\
\hline Triangular imperfections & $\mathrm{x}$ & 2.50 & 0.25 \\
& $\mathrm{y}$ & 2.00 & 0.20 \\
Wavelet imperfections & $\mathrm{x}$ & 2.50 & 0.25 \\
& $\mathrm{y}$ & 0.50 & 0.05 \\
\hline
\end{tabular}

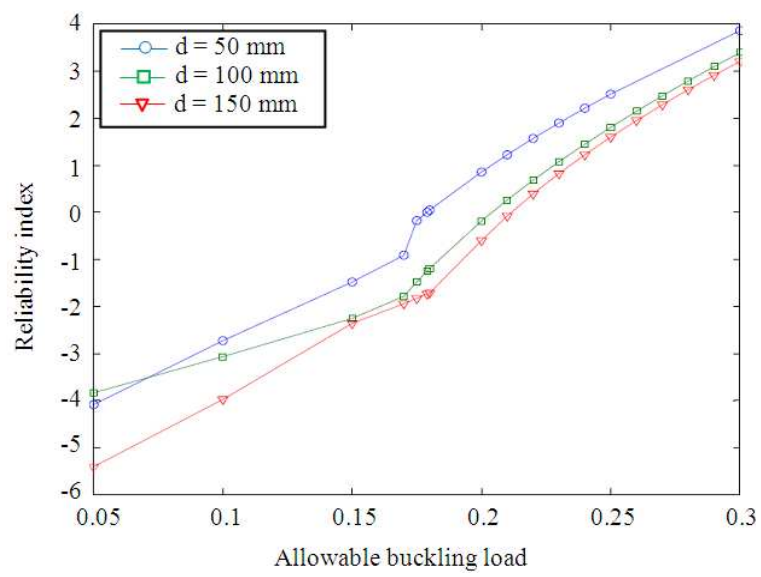

Fig. 6: Reliability index as function of the allowable buckling load, triangular geometric imperfections

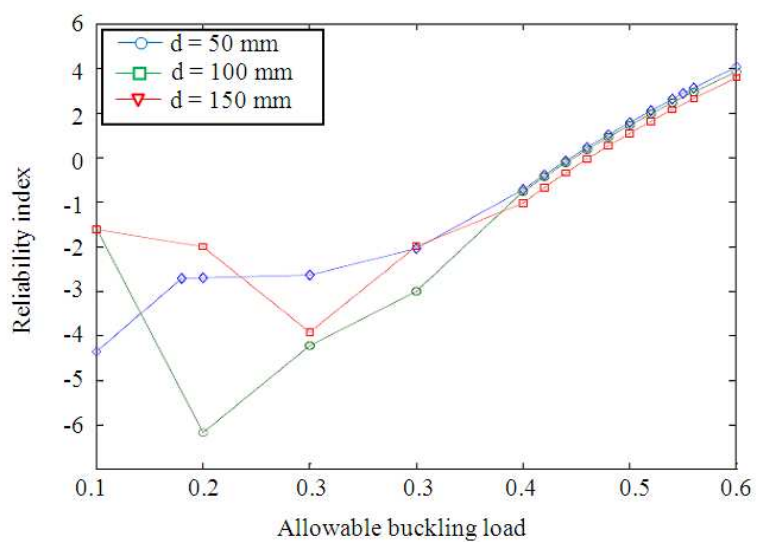

Fig. 7: Reliability index as function of the allowable buckling load, wavelet geometric imperfection

Figure 8 and 9 give the reliability probability in the same conditions than Fig. 6 and 7.

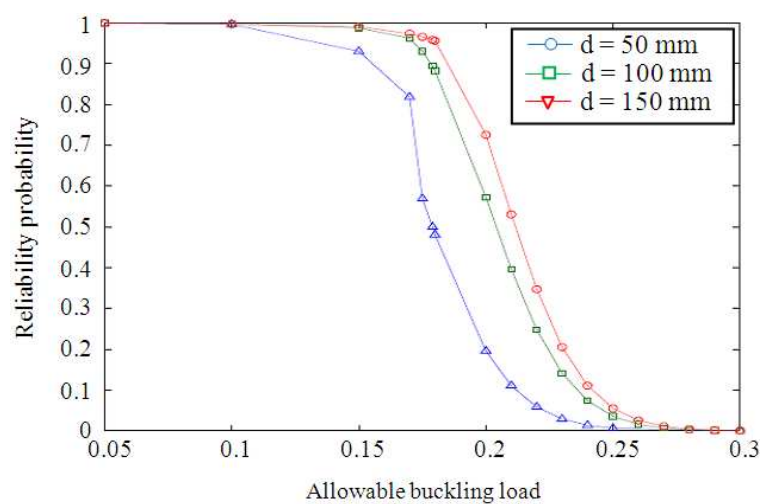

Fig. 8: Reliability probability as function of the allowable buckling load, triangular geometric imperfection

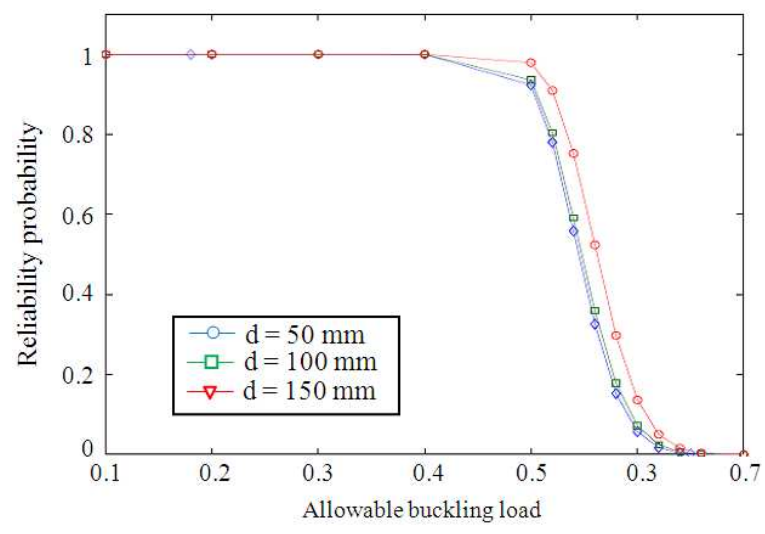

Fig. 9: Reliability probability as function of the allowable buckling load, wavelet geometric imperfection

From comparison of the buckling loads associated to three triangular localized imperfections and to three wavelet ones as given in Fig. 4, one can notice that the triangular imperfections yield the most severe reduction of the shell buckling load. But, if the geometric imperfection amplitude is controlled to not exceed the shell thickness, $\mathrm{A} / \mathrm{t} \leq 1$, than the wavelet defect represents the most prejudicial state as to shell buckling strength. This is why analysis of reliability has been 
considered in these two different zones in terms of imperfection amplitude: $\mathrm{A} / \mathrm{t}$ closer to 0.5 for which the wavelet geometric imperfection shape is used and $\mathrm{A} / \mathrm{t}$ closer to 2 for which the triangular geometric imperfection shape is more selected.

From Fig. 6 and 7 one can notice that the distance $\mathrm{d}$ has a significant influence on reliability index. So, in practice this distance should be carefully selected to enhance reliability design. The pertinent allowable buckling load can be chosen to be 0.175 for $\mathrm{d}=50 \mathrm{~mm}$, this load can be augmented to 0.210 if $\mathrm{d}=150 \mathrm{~mm}$. A significant margin of buckling strength could then be achieved.

Figure 8 and 9 could be used to determine the allowable buckling load for a priori fixed level of reliability.

\section{CONCLUSION}

Finite element simulations have been performed in order to analyze shell buckling as affected by the presence of initial localized geometric imperfections. Elastic thin cylindrical shells subjected to axial compression with three axisymmetric initial imperfections of entering triangular or wavelet shapes have been considered in order to assess reliability of the buckling load design. A set of five factors intervening in the problem have been taken into account during the process of reliability estimation. Fixing the shell aspect ratios yielding the most adverse buckling strength then varying the geometric imperfection characteristics (amplitude and wavelength) as random variables, reliability index and reliability probability have been derived in terms of the allowable design buckling load and the interval distance separating the localized imperfections. It has been shown in the investigated domain of variables that the distance separating the geometric imperfections has a drastic effect on reliability for the triangular imperfections. This effect is rather small for the wavelet imperfection shape. The obtained results may be of significant usefulness if one considers the design purpose of shell structures subjected to axial compression and which are affected by localized geometric imperfections resulting from welding operations. In particular pertinent selection of the distance separating the welds could be performed in order to optimize design reliability.

\section{ACKNOWLEDGEMENT}

The researcher would like to thank warmly professor Alain Combescure from the national institute of applied sciences at Lyon in France for having provided us freely Stanlax software.

\section{REFERENCES}

Arbocz, J. and J.M.A.N. Hol, 1995. Collapse of axially compressed cylindrical shells with random imperfections. Thin-Walled Struct., 23: 131-158. DOI: 10.1016/0263-8231(95)00009-3

Arbocz, J., 1987. Post-buckling behavior of structures, numerical techniques for more complicated structures. Lecture Notes Phys., 288: 83-142. http://adsabs.harvard.edu/abs/1987LNP...288...83A

Arbocz, J., 2005. On a high-fidelity hierarchical approach to buckling load calculations. Proceedings of the European Conference on Spacecraft Structures, Materials and Mechanical Testing 2005 (ESA SP-581), May 10-12, Harvard, Noordwijk, The Netherlands, pp: 54-57. http://articles.adsabs.harvard.edu//full/2005ESASP. 581E..22A/0000022.001.html

Bushnell, D., 1989. Computerized Analysis of Shells, Mechanics of Elastic Stability. Kluwer Academic Publishers, Dordrecht, Boston, London, pp: 245.

Ding, X., R. Coleman and J.M. Rotter, 1996. Technique for precise measurement of large-scale silos and tanks. J. Survey Eng., 122: 14-25. DOI: 10.1061/(ASCE)0733-9453(1996)122:1(14)

Elishakoff, I., S. van Manen, P.G. Vermeulen and J. Arbocz, 1987. First-order second-moment analysis of the buckling of shells with random imperfections. AIAA J., 25: 1113-1117. http://cat.inist.fr/?aModele $=$ afficheN\&cpsidt $=7664$ 641

Godoy, L.A., 1993. On loads equivalent to geometrical imperfections in shells. J. Eng. Mech. ASCE, 119: 186-190. DOI: 10.1061/(ASCE)07339399(1993)119:1(186)

Gusic, G., A. Combescure and J.F. Jullien, 2000. The influence of circumferential thickness variations on the buckling of cylindrical shells under external pressure. Comput. Struct., 74: 461-477. DOI: 10.1016/S0045-7949(99)00053-X

Hansen, J.S., 1977. General random imperfections in the buckling of axially loaded cylindrical shells. AIAA J., 15: 1250-1256. DOI: 10.2514/3.7413

Hubner, A., J.G. Teng and H. Saal, 2006. Buckling behavior of large steel cylinders with patterned welds. Int. J. Pressure Vessels Pip., 83: 13-26. DOI: 10.1016/j.ijpvp.2005.10.003

Hutchinson, J.W., D.B. Muggreridge and R.C. Tennyson, 1971. Effect of a local axisymmetric imperfection on the buckling of a cylindrical shell under axial compression. AIAA J., 9: 48-52. DOI: $10.2514 / 3.6123$ 
Jamal, M., M. Midani, N. Damil and M. Potier-Ferry, 1999. Influence of localized imperfections on the buckling of cylindrical shells under axial compression. Int. J. Solids Struct., 36: 441-446. DOI: 10.1016/S0020-7683(98)00028-6

Khamlichi, A., M. Bezzazi and A. Limam, 2004. Buckling of elastic cylindrical shells considering the effect of localized axisymmetric imperfections. Thin-Walled Struct., 42: 1035-1047. DOI: 10.1016/j.tws.2004.03.008

Khamlichi, A., J. El Bahaoui, L. El Bakkali, M. Bezzazi and A. Limam, 2010. Effect of two interacting localized defects on the critical load for thin cylindrical shells under axial compression. Am. J. Eng. Applied Sci., 3: 464-469. http://www.scipub.org/fulltext/ajeas/ajeas32464469.pdf

Kim, S.E. and C.S. Kim, 2002. Buckling strength of the cylindrical shell and tank subjected to axially compressive loads. Thin-Walled Struct., 40: 329-353. DOI: 10.1016/S0263-8231(01)00066-0

Markus, S., 1988. The Mechanics of Vibrations of Cylindrical Shells. 1st Edn., Elsevier, Amsterdam, New York, ISBN: 10: 0444989102, pp: 159.

Mathon, C. and A. Limam, 2006. Experimental collapse of thin cylindrical shells submitted to internal pressure and pure bending. Thin-Walled Struct., 44: 39-50. DOI: 10.1016/j.tws.2005.09.006
Papadopoulos, V. and M. Papadrakakis, 2005. The effect of material and thickness variability on the buckling load of shells with random initial imperfections. Comput. Methods Applied Mech. Eng., 194: 1405-1426. DOI: 10.1016/j.cma.2004.01.043

Pircher, M., P.A. Berry, X. Ding and R.Q. Bridge, 2001. The shape of circumferential weld-induced imperfections in thin-walled steel silos and tanks. Thin-Walled Struct., 39: 999-1014. DOI: 10.1016/S0263-8231(01)00047-7

Schenk, C.A. and G.I. Schueller, 2003. Buckling analysis of cylindrical shells with random geometric imperfections. Int. J. Non-Linear Mech., 38: 1119-1132. DOI: 10.1016/S00207462(02)00057-4

Van der Heijden, A.M.A., 2008. W.T. Koiter's Elastic Stability of Solids and Structures. Cambridge University Press, New York, ISBN: 13: 9780521515283, pp: 240.

Yamaki, N., 1984. Elastic Stability of Circular Cylindrical Shells. 1st Edn., Elsevier Science Pub. Co., Amsterdam, New York, ISBN: 10: 0444868577, pp: 558. 